\title{
The poly(A)-limiting element enhances mRNA accumulation by increasing the efficiency of pre-mRNA $3^{\prime}$ processing
}

\author{
JING PENG, ${ }^{1,2}$ ELIZABETH L. MURRAY, ${ }^{1,3}$ and DANIEL R. SCHOENBERG ${ }^{1,2,3}$ \\ ${ }^{1}$ Department of Molecular and Cellular Biochemistry, ${ }^{2}$ Ohio State Biochemistry Program, and the ${ }^{3}$ Comprehensive Cancer Center, \\ The Ohio State University, Columbus, Ohio 43210, USA
}

\begin{abstract}
The poly(A)-limiting element (PLE) is a conserved sequence originally found in the $3^{\prime}$ UTR of Xenopus albumin mRNA whose presence restricts the length of the poly $(\mathrm{A})$ tail on both pre-mRNA and fully processed $\mathrm{mRNA}$ to $<20$ nt. Results presented in this study show that the PLE also increases the cytoplasmic level of reporter $\beta$-globin mRNA. Transcription run-on shows this increase was not due to increased reporter gene transcription, and experiments with tetracycline repressor-controlled reporter mRNA showed the PLE does not alter the rate of mRNA decay. Both RT-PCR and RNase protection assay showed the PLE caused a $50 \%$ increase in the $3^{\prime}$ processing of reporter $\beta$-globin mRNA in vivo. This was confirmed in vitro, where PLE-containing RNA was cleaved in HeLa nuclear extract at a rate $80 \%$ faster than a control RNA bearing an inactive element. These results indicate that the PLE regulates the length of the poly(A) tail and the efficiency of $3^{\prime}$ processing. In addition, they show that PLE-containing mRNA with a $<20-n t$ poly(A) tail is as stable as mRNA with a 100- to 200-nt poly(A) tail.
\end{abstract}

Keywords: poly(A); pre-mRNA 3' processing; enhancer; poly(A)-limiting element

\section{INTRODUCTION}

The $3^{\prime}$ processing of most vertebrate pre-mRNAs involves cleavage followed by the addition of a $>200$-nt poly(A) tail through the concerted action of multiple factors binding to AAUAAA upstream of the cleavage site, and to a degenerate U-rich or GU-rich downstream element (Zhao et al. 1999). The poly(A) tail is shortened at various rates during the lifetime of the mRNA, ultimately leading to deadenylation followed by degradation of the mRNA body (Wilusz et al. 2001). We previously showed that Xenopus albumin mRNA has a <20-nt poly(A) tail (Schoenberg et al. 1989; Rao et al. 1996) and identified a unique element, the poly(A)-limiting element, or PLE, as the cis-acting sequence responsible for this short poly(A) phenotype (Das Gupta et al. 1998). PLEs have also been confirmed in transferrin mRNA and the mRNA encoding the transcription factor HIV-EP2 (Gu et al. 1999), and the $3^{\prime}$ ends of a number of genes contain similar sequence elements. By comparing mRNA recovered with oligo(dT) versus a modified form of eIF4E Choi and

Reprint requests to: Daniel R. Schoenberg, Department of Molecular and Cellular Biochemistry, The Ohio State University, 1645 Neil Ave., Columbus, OH 43210-1218, USA; e-mail: schoenberg.3@osu.edu; fax: (614) 292-4118.

Article published online ahead of print. Article and publication date are at http://www.rnajournal.org/cgi/doi/10.1261/rna.2020805.
Hagedorn (2003) also identified mRNAs with short poly(A), but none of these contained sequence elements resembling the PLEs in albumin, transferrin, or HIV-EP2 mRNA. This might represent another class of poly(A)limiting elements or a class of mRNAs that undergoes rapid poly(A) shortening.

Xenopus serum albumin mRNA was the first of the class of short poly(A) mRNAs to be characterized in detail. Both fully processed cytoplasmic albumin mRNA and unspliced albumin pre-mRNA have $<20$-nt poly(A) tails, indicating that the restriction in poly(A) length occurs on nuclear pre-mRNA (Rao et al. 1996). Deletion analysis identified two redundant PLEs in the terminal exon of albumin pre-mRNA (Das Gupta et al. 1998), either of which changed the length of the poly $(\mathrm{A})$ tail on a human $\beta$-globin reporter mRNA from $\sim 200 \mathrm{nt}$ to $<20 \mathrm{nt}$ when placed upstream of a highly efficient synthetic polyadenylation element (SPA) (Levitt et al. 1989; Das Gupta et al. 1998). To function in regulating poly(A) length the PLE must be in the terminal exon, and as long this location is maintained the distance between it and AAUAAA could be changed without affecting its ability to restrict poly(A) to $<20 \mathrm{nt}$ (Das Gupta et al. 2001).

Our previous work on PLE regulation of poly(A) tail length used a modified human $\beta$-globin reporter gene in which transcription was controlled by the CMV promoter, and the last portion of exon 3 was replaced with a multiple cloning site and a synthetic polyadenylation element. This reporter was designed 
to retain spliceable introns in their normal positions within the pre-mRNA, and to remove potential regulatory elements from the $\beta$-globin mRNA $3^{\prime}$ UTR. Using an RT-PCR assay for poly(A) length (Salles et al. 1999) we consistently noticed that $\sim 50 \%$ more of the PCR product from control mRNA was needed to normalize the amount of radioactivity applied to the gel. The results presented here show that this is due to increased accumulation of $\beta$-globin reporter mRNA caused by a PLE-induced increase in the efficiency of $3^{\prime}$ processing. Thus, in addition to regulating the length of the poly $(\mathrm{A})$ tail, the PLE functions in vivo as an enhancer of pre-mRNA $3^{\prime}$ processing.

\section{RESULTS}

\section{The presence of a PLE increases the amount of $\boldsymbol{\beta}$-globin mRNA without affecting reporter gene transcription}

In the experiment in Figure $1, \mathrm{LM}(\mathrm{tk}-)$ cells were transfected with plasmid vectors CMV-glo-SPA (control), which produces $\beta$-globin mRNA with a long, heterogeneous 100-to 200-nt poly(A) tail, or CMV-glo-PLE B-SPA (+PLE), which carries the conserved PLE B element ( $\mathrm{Gu}$ et al. 1999), and produces $\beta$-globin mRNA with a discrete, <20-nt poly(A) tail (Das Gupta et al. 1998). A plasmid expressing firefly luciferase was included as a cotransfected control. The organization of the $\beta$-globin and luciferase plasmids and locations of the RPA probes are shown in Figure 1A and RNase protection assay of cytoplasmic RNA isolated $24 \mathrm{~h}$ after transfection is shown in Figure 1B. Normalizing $\beta$-globin to luciferase mRNA indicated that the latter was increased $\sim 50 \%$ by the presence of a PLE. Transcription run-on was done next to determine if this increase resulted from enhanced reporter gene transcription. In the experiment in Figure 1C nuclei isolated from cells transfected with each of these genes or a $\beta$-globin reporter gene bearing an inactivated PLE (MutG) (Das Gupta et al. 2001) were incubated with $\alpha-\left[{ }^{32} \mathrm{P}\right] \mathrm{UTP}$, and serial twofold dilutions of the resulting radiolabeled transcripts were hybridized to filters containing an excess of filter-bound $\beta$-globin or luciferase cDNAs. Hybridized radioactivity was quantified by PhosphorImager analysis and results with each dilution set were compared. The same ratio of $\beta$-globin to luciferase was obtained for each dilution set for each construct, indicating that the PLE had no effect on reporter gene transcription. Therefore, a PLEinduced increase in transcription was not responsible for the PLE-induced increase in mRNA accumulation.

\section{The PLE does not alter the rate of mRNA decay}

We next examined the possibility that the PLE-stimulated increase in reporter $m R N A$ was due to a PLE-dependent increase in mRNA stability. The reporter genes in Figure 1 were recloned into tetracycline-regulated plasmids and cotransfected with a control plasmid expressing $\beta$-galactosidase from the RSV LTR in antibiotic-free medium. Once steady state was achieved $(24 \mathrm{~h})$ tetracycline was added to repress reporter gene transcription,

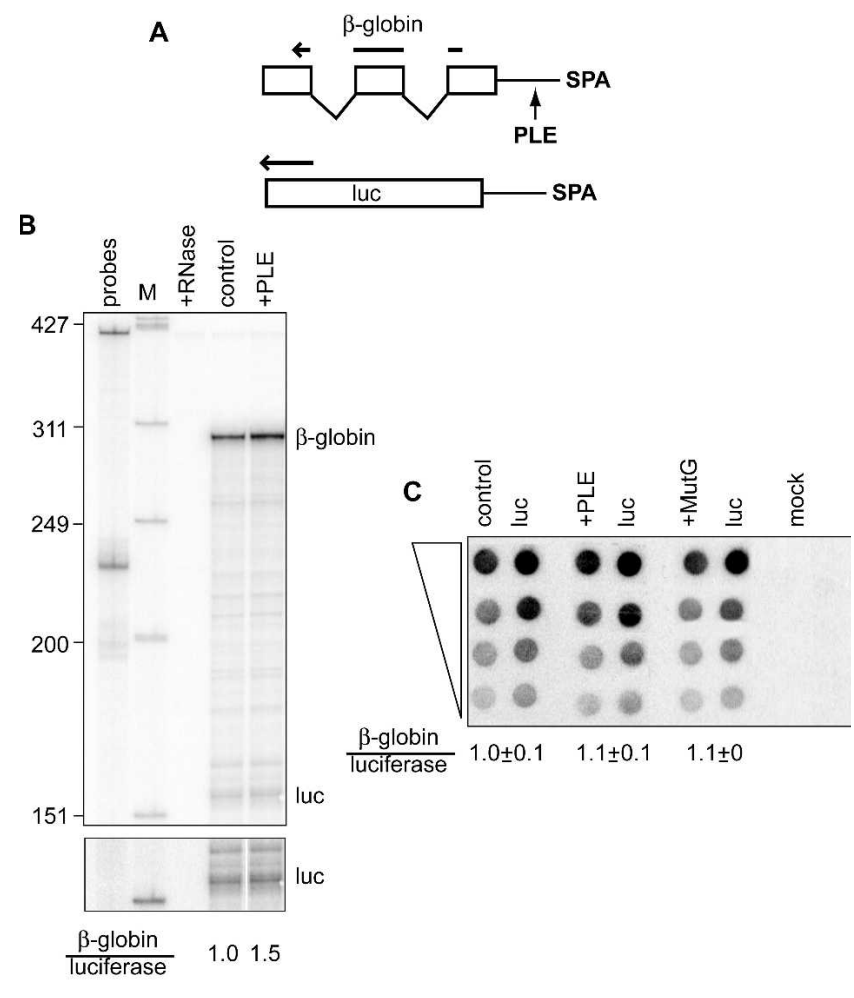

FIGURE 1. Effect of the PLE on the steady-state level of reporter mRNA and reporter gene transcription. $(A)$ The organization of the transfected $\beta$-globin and luciferase genes and the positions of the antisense probes used for RNase protection assays. (B) Four micrograms of cytoplasmic RNA isolated $24 \mathrm{~h}$ after transfection were analyzed by RNase protection assay, and the protected products were separated on a denaturing $6 \%$ polyacrylamide/urea gel. The radiolabeled probes mixed with yeast tRNA were electrophoresed in lane 1 , and the same mixture following RNase digestion was electrophoresed in lane 3. A darker exposure of the portion of the gel corresponding to luciferase mRNA is shown beneath the autoradiogram. The signals for $\beta$-globin mRNA and luciferase mRNA were quantified by PhosphorImager and the relative amount of control versus PLE-containing $\beta$-globin mRNA normalized to the cotransfected luciferase control is shown beneath the autoradiogram. A marker of $\left[{ }^{32} \mathrm{P}\right]$-labeled HinfI digested $\phi X 174$ DNA was electrophoresed in lane 2. The same result has been observed in three independent repeats. (C) Nuclei were harvested from $\mathrm{LM}(\mathrm{tk}-)$ cells $24 \mathrm{~h}$ after transfection with plasmids expressing $\beta$-globin without a PLE (control), with a PLE, or with a mutant PLE that does not function in regulating poly(A) tail length (MutG). A luciferase-expressing plasmid was included in each sample as a cotransfected control, and one set of cultures was mock transfected. Serial twofold dilutions of $\left[{ }^{32} \mathrm{P}\right]$ RNA generated during transcription run-on were hybridized to nylon filters bearing $5 \mu \mathrm{g}$ of $\beta$ globin or luciferase cDNA, and bound RNA was visualized and quantified by PhosphorImager analysis. The same result has been observed in four independent repeats.

and cytoplasmic RNA isolated over the next $22 \mathrm{~h}$ was assayed by RPA for $\beta$-globin and $\beta$-galactosidase mRNA. The autoradiograms for both $\beta$-globin and $\beta$-galactosidase mRNA are shown in Figure 2A, and the decay curves for control and PLE-containing $\beta$-globin mRNA normalized to $\beta$-galactosidase mRNA are shown in Figure $2 B$. Even though the PLE-containing mRNA has $<20$ nt of poly(A) it was as stable as the control, with both 
A

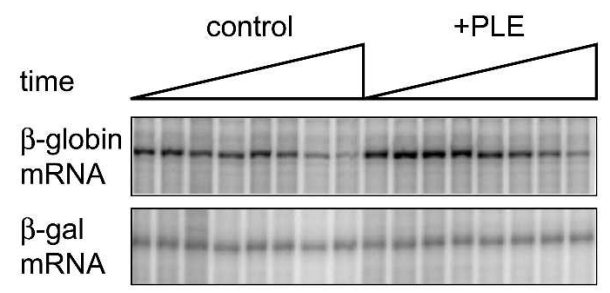

B

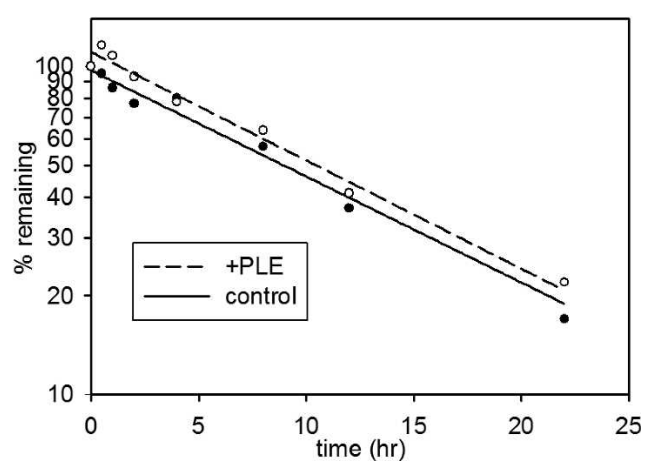

FIGURE 2. The PLE does not alter the rate of mRNA decay. A line of $\mathrm{LM}(\mathrm{tk}-)$ cells was prepared that was stably transfected with a plasmid expressing tetracycline repressor. These were cotransfected in medium lacking tetracycline with tetracycline-regulated plasmids containing the human $\beta$-globin genes in Figures 1 and 2 under control of a tetracycline-regulated promoter and a plasmid expressing $\beta$-galactosidase under control of the RSV-LTR. Tetracycline was added at time 0 and $\beta$-globin and $\beta$-galactosidase mRNA levels in cytoplasmic RNA isolated at the indicated times were determined by RNase protection assay and PhosphorImager analysis. (A) The autoradiogram for each mRNA. (B) The decay curves fitted to linear regression lines.

mRNAs decaying with a 10-h half-life. Thus the PLE-induced increase in reporter mRNA accumulation was not due to increased mRNA stability, and importantly, PLE-containing mRNA with a $<20$-nt poly(A) tail is as stable as mRNA with a 100 - to 200 -nt poly(A) tail.

\section{The PLE enhances $3^{\prime}$ processing}

Upstream elements often modulate the efficiency of pre-mRNA $3^{\prime}$ processing (Zhao et al. 1999), and the fact that the PLE must be in the last exon to regulate poly(A) tail length (Das Gupta et al. 2001) raised the possibility that it might also enhance the efficiency of $3^{\prime}$ processing. The first experiment to test this used an RT-PCR approach similar to that used by Juge et al. (2002) to examine the role of poly(A) polymerase on cleavage efficiency in vivo. This assay quantifies the relative amount of pre-mRNA that has not undergone cleavage and polyadenylation by comparing the recovery of RT-PCR products generated by priming reverse transcription with an antisense oligonucleotide complementary to sequences downstream of the cleavage site. Thus, an increase in $3^{\prime}$ processing (i.e., cleavage) efficiency will appear as a decrease in product generated from the uncleaved premRNA. The locations of the primers used for this analysis are shown in Figure 3A. Since both the $\beta$-globin and luciferase constructs used a SPA for $3^{\prime}$ processing, a single primer complementary to the $3^{\prime}$ portion of SPA primed CDNA synthesis for both $\beta$-globin and luciferase RNA. cDNA was then PCR amplified using the $5^{\prime}-\left[{ }^{32} \mathrm{P}\right]$-labeled primers to $\beta$-globin or luciferase mRNA and the downstream SPA antisense primer. Amplification was limited to 13 cycles, which was empirically determined to lie within the linear range, and each set of reactions included a standard curve of plasmid DNA. Finally, to rule out any contribution from contaminating plasmid DNA, a control prepared without reverse transcriptase was included for each sample.

A
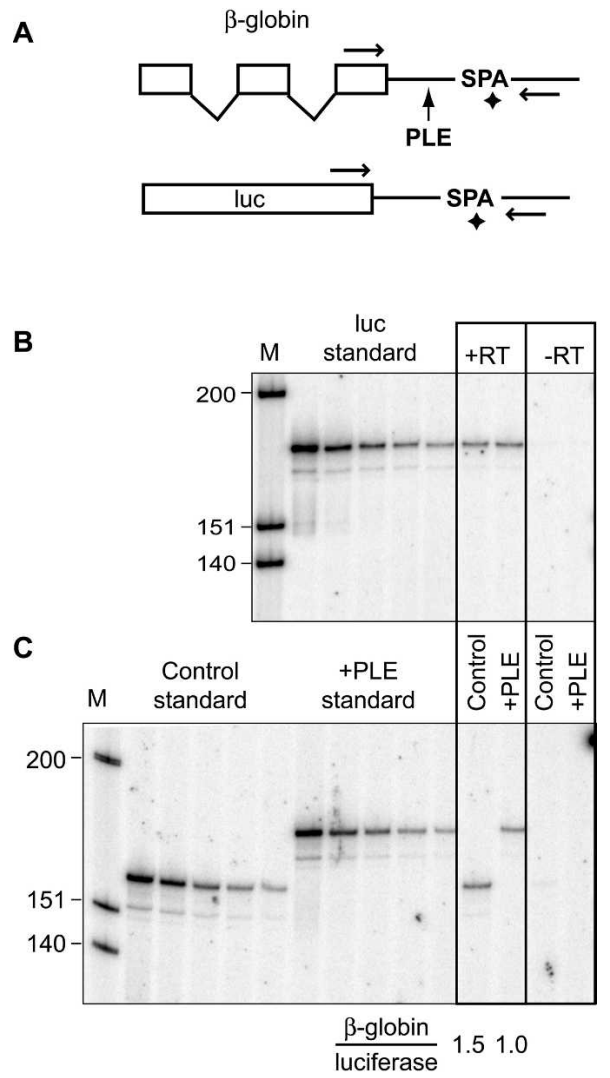

FIGURE 3. RT-PCR analysis of pre-mRNA $3^{\prime}$ processing. (A) The locations of primers used for reverse transcription and PCR amplification are indicated on a diagram of the reporter $\beta$-globin and control luciferase genes. The relative location of the cleavage site is identified with a diamond $(\diamond)$. Nuclear RNA from cells transfected with the indicated plasmids was annealed to a primer complementary to the $3^{\prime}$ portion of the synthetic polyadenylation element (SPA) and incubated with $(+\mathrm{RT})$ or without $(-\mathrm{RT})$ reverse transcriptase in the first reaction. The cDNA products were PCR amplified using the same $3^{\prime}$ primer and $5^{\prime}-\left[{ }^{32} \mathrm{P}\right]$-labeled primers for $\beta$-globin exon $3(B)$, or the $3^{\prime}$ end of the luciferase gene $(C)$. A parallel set of PCR reactions was performed with $20,10,5,2.5$, and 1.25 pg of each transfected plasmid to generate a standard curve for quantifying the products of the PCR reaction. These were applied to the left portion of each gel. The reaction products were applied to a $6 \%$ polyacrylamide/urea gel, and visualized and quantified by PhosphorImager analysis. The relative amounts of each of the PCR-amplified products are indicated beneath the autoradiograms. Lane $1(\mathrm{M})$ on each gel contains a marker of $\left[{ }^{32} \mathrm{P}\right]$-labeled Hinfl digested $\phi X 174$ DNA. The same result was obtained in three independent repeats. 
The PCR-amplified products separated on a denaturing $6 \%$ polyacrylamide gel are shown in Figure 3B for luciferase premRNA and in Figure 3C for $\beta$-globin pre-mRNA. The RT-PCR products prepared without $(-\mathrm{RT})$ and with $(+\mathrm{RT})$ reverse transcriptase are in the last four lanes. No $\beta$-globin or luciferase products were detected if reverse transcriptase was omitted from the reaction. RT-PCR of nuclear RNA generated a single product for each gene, with that from the PLE-containing RNA running more slowly than the control because the 23-bp PLE lay between the primer binding site in exon 3 and the downstream primer binding site. After normalizing to the plasmid standards and the luciferase control, the amount of uncleaved control pre-mRNA was $\sim 50 \%$ greater than the amount of uncleaved PLE-containing pre-mRNA, a result that mirrors the PLE-stimulated increase in $\beta$-globin mRNA in Figure 2.

Because the RT-PCR assay provides an indirect assessment of in vivo cleavage efficiency we next used an RNase protection assay to confirm that the PLE enhanced the efficiency of $3^{\prime}$ processing in vivo. The location of the PLE close to AAUAAA in the constructs used for the preceding experiments

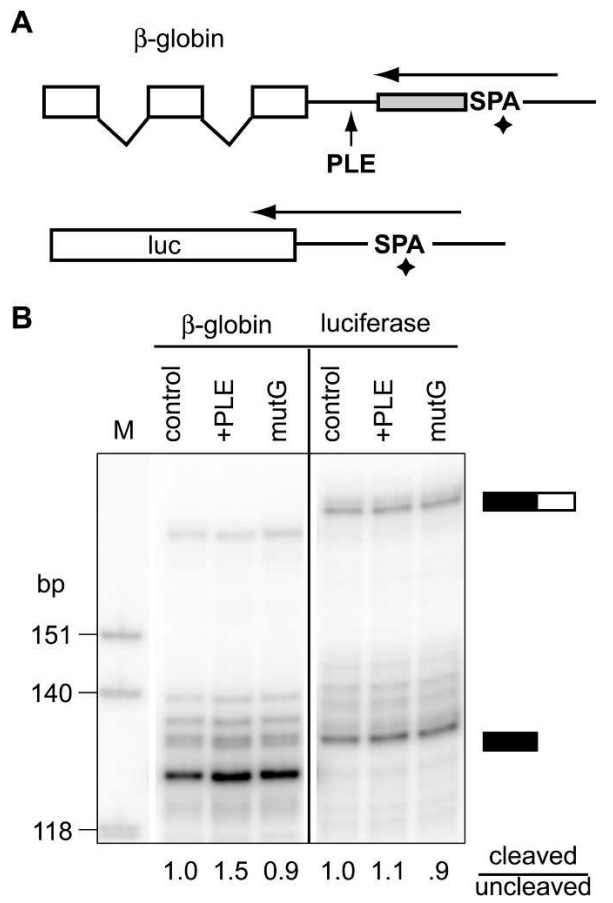

FIGURE 4. RNase protection analysis of pre-mRNA $3^{\prime}$ processing. (A) Two hundred base pairs of $\phi X 174$ DNA were inserted upstream of the synthetic polyadenylation element to generate a target for RNase protection assay (gray box). The location of the cleavage site is identified with a diamond $(\diamond) .(B)$ Nuclear RNA was recovered as in Figure 3 from cells transfected with the indicated $\beta$-globin reporter plasmids plus the luciferase cotransfected control. The recovered RNA was analyzed separately for $\beta$-globin and luciferase by RNase protection assay using the probes shown schematically in $A$. The positions of the uncleaved and cleaved pre-mRNA are indicated with filled and open boxes and the ratios of cleaved to uncleaved products of $\beta$-globin and luciferase mRNA are shown beneath the autoradiograms. The same result has been obtained in four independent repeats. complicated efforts to design a single probe that would hybridize to each reporter mRNA. To address this we took advantage of previous work showing that additional sequence can be inserted between the PLE and AAUAAA without affecting PLE regulation of poly(A) length (Das Gupta et al. 2001). The diagram in Figure 4A shows the location of a 200-bp insert of $\phi X 174$ DNA between the PLE and AAUAAA and the RNase protection probe designed to detect both precursor and cleaved pre-mRNA. In the experiment in Figure 4B $\beta$-globin reporter genes with no added sequence other than this (control), with the PLE or with the inactive MutG element were cotransfected with a luciferase control, and nuclear RNA was assayed for the presence of uncleaved and cleaved pre-mRNAs. When each of the bands was quantified by PhosphorImager there was 1.5 times more cleaved PLE-containing reporter $\beta$-globin mRNA than the control that lacked any added element. This enhancement in $3^{\prime}$ processing efficiency was lost when the PLE was replaced with the inactive MutG element. Together with the results in Figure 3 these data indicate that, in addition to regulating the length of added poly(A), the PLE also enhances the efficiency of $3^{\prime}$ processing.

\section{The PLE increases the rate of cleavage in vitro}

The impact of the PLE on the efficiency of $3^{\prime}$ processing was next analyzed in vitro using HeLa nuclear extract (Keller 1995). In Figure 5A transcripts without or with a single PLE upstream of the SPA synthetic polyadenylation element were incubated with HeLa nuclear extract over a 2-h period, then separated on a $6 \%$ denaturing polyacrylamide/urea gel and analyzed by PhosphorImager. A graphical plot of the percent of cleaved product over time showed that the presence of a single PLE had no effect on the rate of product accumulation (Fig. 5B). Because the overall cleavage efficiency of these transcripts was low compared to an adenovirus L3 control (not shown) we reasoned that the efficiency of PLE recognition in vitro might also be low. It is common to employ multiple elements on reporter RNAs, and the experiment in Figure 5C,D compared the impact of four tandem PLEs versus four repeats of the inactive MutG element on $3^{\prime}$ processing. In contrast to results with a single PLE, four copies of the PLE increased the rate of cleavage 2.7-fold compared to the inactive MutG element, a result that is consistent with our in vivo data. To ensure that the difference observed here was not due to lower stability of the MutG-containing cleavage product we incubated transcripts corresponding to each of the $4 \times$ PLE and MutG cleavage products under the same conditions (Fig. 5E) together with a control transcript of Renilla luciferase mRNA. The results obtained for the $4 \times$ PLE and MutG RNAs at each time point normalized to Renilla luciferase RNA are shown graphically in Figure 5F. There was no difference in the in vitro decay of the cleaved $4 \times$ PLE RNA versus $4 \times$ MutG RNA, indicating that the increased accumulation of $4 \times$ PLE RNA in Figure 5C,D resulted from a PLE-induced increase in the efficiency of $3^{\prime}$ processing. 


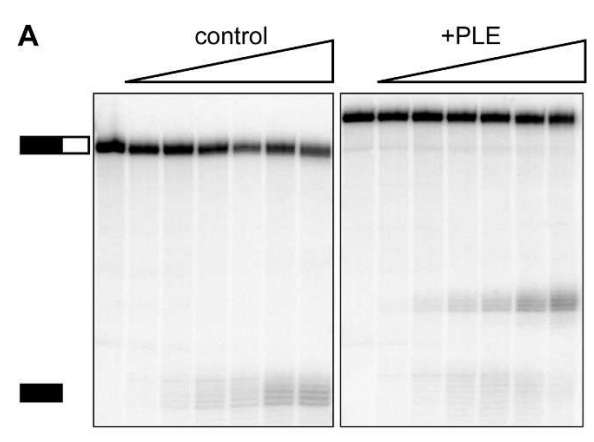

B

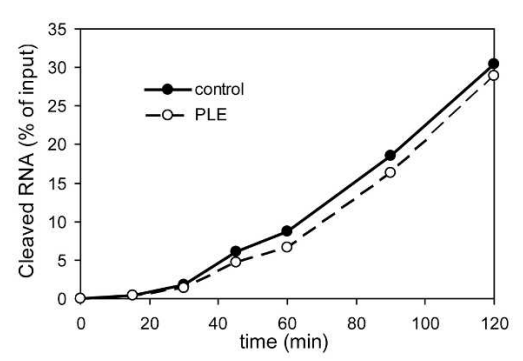

C

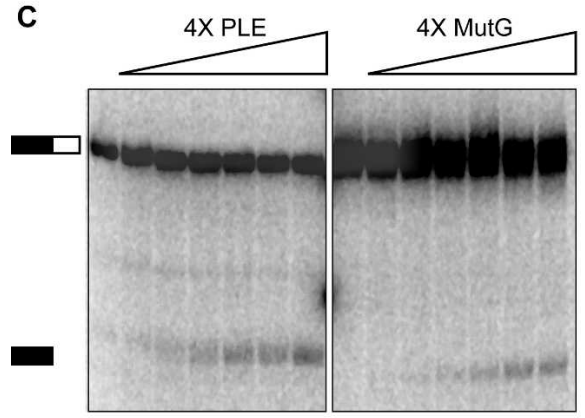

E

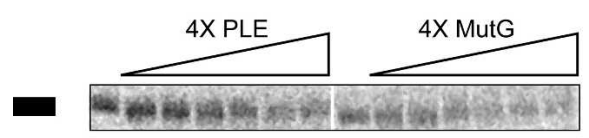

Rluc

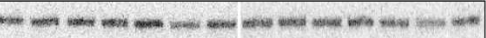

D

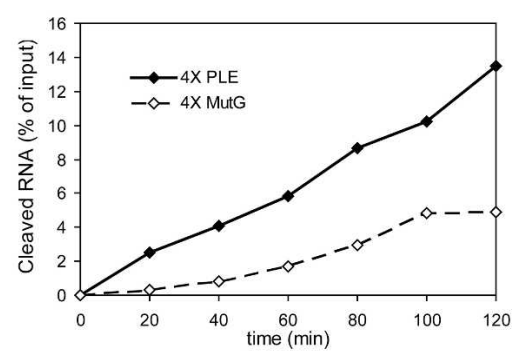

$\mathbf{F}$

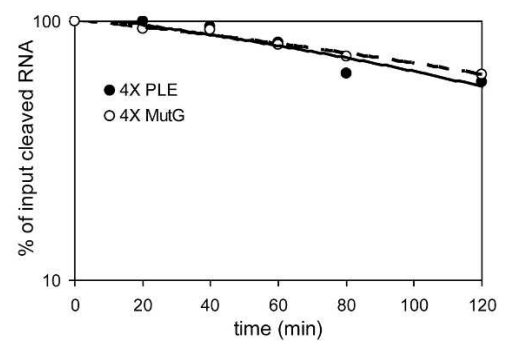

FIGURE 5. Impact of the PLE on $3^{\prime}$ processing in vitro. $(A)\left[{ }^{32} \mathrm{P}\right]$-labeled transcripts containing the $3^{\prime}$ end and SPA processing sites of the control and PLE-containing plasmids used in Figure 2 were incubated for $0-120 \mathrm{~min}$ in HeLa nuclear extact. Recovered RNA was separated on a denaturing $6 \%$ polyacrylamide/urea gel and radiolabeled input and cleaved RNA were visualized by PhosphorImager analysis. The same result was obtained in three independent repeats. $(B)$ The radioactivity in each of the cleaved products was quantified and the results graphed as percent of input RNA as a function of time. $(C)\left[{ }^{32} \mathrm{P}\right]$-labeled transcripts containing four tandem copies of the PLE $(4 \times$ PLE) or the inactive MutG $(4 \times$ MutG) sequence elements plus a synthetic polyadenylation element (SPA) were incubated for 0-120 min with HeLa nuclear extract and separated as in $A$. The rate of cleaved product accumulation for each RNA is shown graphically in $D$, where the accumulation of cleaved RNA is plotted as percent of input RNA as a function of time. Shown are typical data from three independent repeats. $(E)\left[{ }^{32} \mathrm{P}\right]$-labeled transcripts corresponding to the cleaved RNAs generated from $4 \times$ PLE or $4 \times$ MutG were incubated together with a transcript for Renilla luciferase for 0-120 min under the conditions used in $A$ and $C .(F)$ The results obtained for $4 \times$ PLE and $4 \times$ MutG RNA at each time point were normalized to those of Renilla luciferase RNA and plotted as a percent of input RNA versus time.

\section{DISCUSSION}

Work presented here shows that the PLE stimulates a posttranscriptional increase in steady-state mRNA by enhancing the rate of $3^{\prime}$ processing. This feature of the PLE acts in addition to regulating the length of the poly(A) tail. While the $50 \%$ increase observed here is small compared to that of viral enhancers such as those found in SV40 and adenovirus (Edmonds 2002), it is on the same scale as the twofold increase in prothrombin mRNA observed in hereditary thrombophilia, where a mutation changing the GA dinucleotide at the cleavage site to a CA dinucleotide increases prothrombin mRNA and protein expression by increasing $3^{\prime}$ processing efficiency (Gehring et al. 2001).

The mechanism by which the PLE regulates $\operatorname{poly}(\mathrm{A})$ tail length is still unknown. Although previous work identified U2AF as a PLE-binding protein and identified a role for this protein in modulating the function of the PLE (Gu and Schoenberg 2003) it is not directly involved in regulating poly(A) tail length. Although the PLE can stimulate $3^{\prime}$ processing in HeLa nuclear extract (Fig. 5B), we have not achieved similar success in PLE regulation of poly(A) tail length in vitro. The reason for this remains unknown, but may involve coupled reactions that are not replicated in this system. Nevertheless, the current study adds another dimension to understanding the short poly(A) phenotype. It is generally accepted that mRNAs undergo poly(A) shortening prior to degradation of the mRNA body (Wilusz et al. 2001), and the rate of deadenylation correlates with the ultimate decay rate of the mRNA body. Since the oligoadenylate that remains after deadenylation but before degradation of the mRNA body is comparable in size to the <20-nt poly(A) tail on PLE-containing mRNA, one might assume that the latter would be unstable. This is not the case; both control and PLE-containing mRNAs decay with a 10-h half-life (Fig. 2). The stability of mRNA with a $<20$-nt poly(A) tail seemingly contradicts recent work demonstrating a poly(A) length-dependent shift in the mRNP, from a translating, polysome-bound state to cytoplasmic foci (P-bodies), where mRNA is decapped and degraded by Xrn1 (Tharun and Parker 2001; Sheth and Parker 2003). This seeming disparity can be explained by recent work from our laboratory showing that PLE-containing mRNAs are translated as efficiently in vivo as controls with 10 - to 200-nt poly(A) tails (Peng and Schoenberg 2005). 
Why cells use a mechanism like the PLE to regulate poly(A) tail length remains to be determined. However, several recent findings may shed new light on this. As noted above, the overall translation efficiency of PLE-containing mRNA is similar to that of mRNA with long poly(A). A somewhat smaller portion of these short poly(A) mRNAs sediment with the heaviest polysome fractions, so an increase in steady mRNA may function to offset this effect. In addition, a recent report by Lewis et al. (2005) identified thousands of mRNAs as potential targets for regulation by miRNAs, and a search of the Sanger miRNA database identified several miRNAs with sequence complementarities to each of the PLEs we have characterized. These data raise the possibility that one or more miRNAs may be involved in either PLE regulation of $\operatorname{poly}(\mathrm{A})$ length or in the translation of these short poly(A) mRNAs.

\section{MATERIALS AND METHODS}

\section{Plasmid constructs}

The construction of the plasmids CMV-glo-SPA and CMV-glo-PLE B-SPA and the inactive MutG form of the PLE were described previously (Das Gupta et al. 1998, 2001). Briefly, a plasmid bearing the human $\beta$-globin gene under control of the CMV promoter was cut in exon 3 (position 1497) by EcoRI. This was ligated into a modified pUC18 that was engineered to introduce an in-frame stop codon upstream of the multiple cloning site. A double-stranded oligonucleotide corresponding to the SPA (Levitt et al. 1989) was inserted between the SalI and SphI sites in the multiple cloning site to create CMV-glo-SPA. PLE B and MutG elements were inserted as doublestranded oligonucleotides into the multiple cloning site between the stop codon and the SPA. A PLE-containing plasmid with an additional 200 bp of $\phi X 174$ DNA (Das Gupta et al. 2001) was digested with XbaI to generate a 158-bp fragment that was inserted into the $\mathrm{XbaI}$ site of each of the $\beta$-globin reporter genes to generate the plasmids used in Figure 4. To prepare the luciferase control (CMVluc-SPA) CMV-glo-SPA was digested with Asp718 and end filled with Klenow fragment of DNA polymerase followed by digestion with NcoI to remove the globin cassette, leaving intact the CMV promoter and SPA $3^{\prime}$ processing element. The luciferase gene was obtained by digesting pGTetOßAc.luc3 (generously provided by José GarciaSanz) with XbaI followed by end filling using Klenow fragment of DNA polymerase and digestion with NcoI. The recovered luciferase gene was cloned into the CMV promoter-containing constructs prepared above.

To prepare tetracycline-regulated plasmids, pGTetOßAc-globinSPA and pGTetOßAc-globin-PLE-SPA were first digested with HindIII, recovered with the Qiagen PCR cleanup kit, and end filled with Klenow fragment. The linearized plasmids were digested with NcoI, and digests were separated by agarose gel electrophoresis. Bands containing the desired $\beta$-globin $( \pm P L E)$ were excised from the gel and DNA was purified with a gel extraction kit (Qiagen). pTREmyc was prepared for ligation by double digestion with HincII and NcoI followed by agarose gel electrophoresis and excision of the backbone-containing fragment, which was subsequently purified as above. pCMVTet-globin-SPA and pCMVTetglobin-PLE-SPA were created by the ligation of the pTREmyc backbone to inserts derived from pGTetOßAc-globin-SPA and
pGTetOßAc-globin-PLE-SPA, respectively. To generate a probe for RNase protection assay of the mRNAs analyzed in Figure 4, CMVglo-SPA with added $\phi X 174$ sequence was completely digested with HindIII and partially digested with XbaI. The 225-bp fragment that contained the $\phi X 174$ and SPA sequences was ligated into pBluescript $\mathrm{SK}(+)$ (pBSK) that was digested with $\mathrm{XbaI}$ and HindIII to generate pBSX200-SPA. To generate a probe for uncleaved and cleaved luciferase mRNA, a fragment containing the $3^{\prime}$ end of the coding region of firefly luciferase and SPA was amplified by PCR from plasmid CMV-luc-SPA using primers JP29 (5'-GTAAAACGACGGCCAG TGCCAAG) and JP30 (5'-CTTGGTACCGAAAGGTCTTACC). This was ligated into pBluescript $(\mathrm{SK}-)$ that was digested with KpnI and HindIII to generate plasmid pBSLucSPA.

The plasmids used as templates to generate capped RNAs with or without a PLE upstream of the SPA used in the in vitro cleavage assay in Figure 5A were constructed as follows: CMV-glo-SPA and CMV-glo-PLEB-SPA were digested with HindIII, followed by treatment with Klenow fragment of DNA polymerase to remove overhanging nucleotides, then digested with EcoRI. The small fragments (91 bp from CMV-glo-SPA and 108 bp from CMV-glo-PLEB-SPA) were ligated into pGEM3Z that was digested with EcoRI and SmaI. The plasmids obtained above were named pGgloEx3SPA and pGgloEx3PLEBSPA. For transcription these plasmids were linearized by digestion with Hind III and transcribed with T7 RNA polymerase. The sizes of control transcript and cleavage product were $140 \mathrm{nt}$ and $68 \mathrm{nt}$, respectively, and the sizes of PLE-containing transcript and cleavage product were $182 \mathrm{nt}$ and $85 \mathrm{nt}$, respectively. Plasmids with four copies of PLE B or MutG upstream of the SPA synthetic polyadenylation element were used to generate capped RNAs used in the in vitro cleavage assay in Figure 5C. To generate a fragment with multiple copies of PLE B, primers YC1 $\left(5^{\prime}-\mathrm{TT}\right.$ TCTAGAAAGTTCCTTCAGCTGAA) and Joy30 (5'-CCTCTAGAG CTCTTTTCAGCTGAAGGAACTTT) were annealed, digested with $\mathrm{XbaI}$, then ligated together. The ligated product was treated with T4 DNA polymerase to remove the protruding ends, then cloned into SmaI-digested pGem $3 Z$ to generate pGem(PLE)4. The same approach used primers YC2 ( $5^{\prime}$-TTTCTAGAAAGTACGTACAGCT GAA) and YC3 (5'-CCTCTAGACTCTTTTCAGCTGTACGTAC) to generate a plasmid (pGem(MutG)4), containing four copies of the inactive MutG element. The fragments containing four copies of PLEB or MutG recovered from pGEM(PLEB) 4 and pGEM(MutG) 4 by digestion with EcoRI and HincII were ligated into pGgloEx3SPA that was digested with the same enzymes. For transcription these plasmids were linearized by digestion with HindIII and transcribed with T7 RNA polymerase. The sizes of $4 \times$ PLE transcript and cleavage product were $252 \mathrm{nt}$ and $182 \mathrm{nt}$, respectively, and the sizes of $4 \times$ mutG transcript and cleavage product were $247 \mathrm{nt}$ and $176 \mathrm{nt}$, respectively. To generate the transcripts used in Figure 5E, these plasmids were linearized by digestion with BglII, which cuts at the cleavage site within the SPA sequence.

\section{Cell transfection, RNA isolation, and RNase protection assay}

$\mathrm{LM}(\mathrm{tk}-)$ cells were obtained from the American Type Culture Collection and maintained in Dulbecco's Minimal Essential Medium (DMEM) with $10 \%$ fetal calf serum (FBS) and $2 \mathrm{mM}$ glutamine. One day before transfection, $8 \times 10^{5}$ cells were seeded into $60-\mathrm{mm}$ dishes. In all experiments except those in Figure 3 cells 
were transfected with $5 \mu \mathrm{g}$ of plasmid DNA plus $30 \mu \mathrm{L}$ of Superfect (Qiagen) following the manufacturer's recommended protocol. In the experiment in Figure $2 \mathrm{LM}(\mathrm{tk}-)$ cell lines expressing the tetracycline repressor were generated as described previously (Yang et al. 2004) using a plasmid expressing the tetracycline repressor and a hygromycin resistance gene and clonal selection in hygromycin. These cells were transfected as above in medium lacking tetracycline, and reporter gene transcription was terminated at time 0 by adding $1 \mu \mathrm{g} / \mathrm{mL}$ of tetracycline to the medium. Nuclear and cytoplasmic RNA were isolated using the Stratagene Absolutely RNA RT-PCR miniprep kit. $\beta$-Globin, luciferase, and $\beta$-galactosidase mRNAs were quantified by RNase protection assay using the RPAIII kit (Ambion). In Figure 1 the antisense $\beta$-globin cDNA probe spanning $40 \mathrm{bp}$ of exon1, $222 \mathrm{bp}$ of exon 2, and 42 bp of exon 3 of $\beta$-globin mRNA was cloned into pTopoII. $\left[{ }^{32} \mathrm{P}\right]$-labeled $\beta$-globin antisense RNA was transcribed from EcoRV cut plasmid with SP6 polymerase. The luciferase probe spanned the first $156 \mathrm{bp}$ of the coding region cloned into pBluescript $(\mathrm{SK}-) .\left[{ }^{32} \mathrm{P}\right]$-labeled luciferase antisense RNA was transcribed from EcoRI cut plasmid with T3 polymerase. For the experiment in Figure 4 the template for the $\beta$-globin $3^{\prime}$ end probe was prepared by PCR amplification of pBSX200-SPA using primers for the T7 promoter and JP31 (5'-AATGAATTC GAAGTGGACTGCTGGCGGAA). This fragment was digested by EcoRI and transcribed by T7 RNA polymerase. This probe yielded protected products of $169 \mathrm{nt}$ and $132 \mathrm{nt}$, respectively, for $\beta$-globin pre-mRNA and mature mRNA. The probe for $3^{\prime}$ processing of luciferase mRNA was prepared by linearizing pBSlucSPA with Asp718 (Roche) and transcription with T3 DNA polymerase. The protected products for luciferase pre-mRNA and mature mRNA were $179 \mathrm{nt}$ and $143 \mathrm{nt}$, respectively. The protected products were electrophoresed on a denaturing $6 \%$ polyacrylamide/ urea gel, which was dried and visualized by PhosphorImager for quantitative data analysis.

\section{RT-PCR assay for $3^{\prime}$ processing}

The RT-PCR assay to quantify the degree of $3^{\prime}$ processing was adapted from Juge et al. (2002). Two micrograms of nuclear RNA were reverse transcribed at $42^{\circ} \mathrm{C}$ for $1 \mathrm{~h}$ in a $20 \mu \mathrm{L}$ reaction containing RT buffer provided with the enzyme, $0.5 \mathrm{mM}$ dNTP, $10 \mathrm{mM}$ dithiothreitol, 15 pmol of primer JP29 complementary to the $3^{\prime}$ portion of the synthetic polyadenylation element (5'-GTAAAACGACGGC CAGTGCCAAG), 50 units of Superscript II RT (Invitrogen), and 10 units of RNaseOut (Invitrogen). One microliter of the RT product was amplified in a $10 \mu \mathrm{L}$ PCR reaction using 13 cycles of $50 \mathrm{sec}$ at $94^{\circ} \mathrm{C}$, 50 sec at $58^{\circ} \mathrm{C}$, and $30 \mathrm{sec}$ at $72^{\circ} \mathrm{C}$ with Taq buffer provided with the enzyme, $2 \mathrm{mM} \mathrm{MgCl}_{2}, 0.2 \mathrm{mM}$ dNTP, 15 pmol of each primer, and 1 unit of Taq DNA polymerase (Invitrogen). The primers XG1 and JP29 were used for amplification of $\beta$-globin pre-mRNA, and the primers used for amplification of luciferase pre-mRNA were BVLuc1 (5'-TCGACGCAAGAAAAATCAGAGAGA) and JP29. XG1 and BVLucl were $5^{\prime}$-end labeled using $\gamma$ - $\left[{ }^{32} \mathrm{P}\right]$ ATP plus T4-polynucleotide kinase (Roche). To verify the linearity of the PCR conditions, 20, $10,5,2.5$, and 1.25 pg of plasmid DNA pCMVGloSPA, pCMVGloPLEBSPA, and pCMVLucSPA were amplified synchronously. Three microliters of each PCR product were electrophoresed on a denaturing $6 \%$ polyacrylamide/urea gel, and radiolabeled products were visualized by PhosphorImager analysis.

\section{Nuclear transcription run-on assay}

Some $5.0 \times 10^{6} \mathrm{LM}(\mathrm{tk}-)$ cells were seeded in a $150-\mathrm{mm}$ dish and cotransfected with $10 \mu \mathrm{g}$ of CMV-glo-SPA or CMV-glo-PLE-SPA or CMV-glo-MutG-SPA and $10 \mu \mathrm{g}$ of CMV-luc-SPA plasmid DNA. Twenty-four hours after transfection, the cells were washed twice with ice-cold PBS, scraped into $10 \mathrm{~mL}$ cold PBS, and collected by centrifugation at $200 \mathrm{~g}$ for $5 \mathrm{~min}$ at $4^{\circ} \mathrm{C}$ in a Sovall HS- 4 rotor. The cell pellet was resuspended in lysis buffer $(10 \mathrm{mM}$ Tris- $\mathrm{HCl}$ at $\mathrm{pH} 7.5$, $10 \mathrm{mM} \mathrm{NaCl}^{3} \mathrm{mM} \mathrm{MgCl}_{2}$, and $\left.0.5 \%(\mathrm{v} / \mathrm{v}) \mathrm{NP}-40\right)$ and incubated on ice for 5-10 min to break the cytoplasmic membrane. The nuclei were collected by centrifugation at $500 \mathrm{~g}$ for $5 \mathrm{~min}$ at $4^{\circ} \mathrm{C}$ in a Sovall HS-4 rotor, and resuspended in $200 \mu \mathrm{L}$ glycerol storage buffer $(50 \mathrm{mM}$ Tris- $\mathrm{HCl}$ at $\mathrm{pH} 8.0,40 \%$ glycerol, $5 \mathrm{mM} \mathrm{MgCl}_{2}$, and $0.1 \mathrm{mM}$ EDTA). The nuclei were stored at $-80^{\circ} \mathrm{C}$. For the transcription assay, $50 \mu \mathrm{L}$ $\left(1.2 \times 10^{6}\right)$ of resuspended nuclei obtained above were incubated with an equal volume of $2 \times$ run-on reaction buffer $(10 \mathrm{mM}$ Tris/ $\mathrm{HCl}$ at pH 8.0, $5 \mathrm{mM} \mathrm{MgCl}_{2}, 0.3 \mathrm{M} \mathrm{KCl}, 1 \mathrm{mM}$ CTP, GTP, ATP, $1 \mu \mathrm{M}$ unlabeled UTP, $60 \mu \mathrm{Ci}$ of $\alpha-\left[{ }^{32} \mathrm{P}\right] \mathrm{UTP}$ [3000 Ci/mmol]) for $30 \mathrm{~min}$ at $30^{\circ} \mathrm{C}$. The radiolabeled nuclear RNA was recovered with $1 \mathrm{~mL}$ TRIzol and resuspended in $10 \mu \mathrm{L}$ water, followed by treatment with 10 units of RQ1 DNase (Promega) for $30 \mathrm{~min}$ at $37^{\circ} \mathrm{C}$. Five micrograms heat denatured plasmids containing $\beta$-globin or firefly luciferase cDNA were applied to MSI nylon transfer membrane (Osmonics) using a dot blot apparatus followed by UV cross-linking. The membranes were prehybridized for $2 \mathrm{~h}$ at $42^{\circ} \mathrm{C}$ in formamide hybridization buffer ( $50 \%$ formamide, $5 \times$ SSPE, $5 \times$ Denhardt's solution, $1 \%$ sodium dodecylsulfate [SDS], $100 \mu \mathrm{g} / \mathrm{mL}$ salmon sperm DNA [Invitrogen]) followed by hybridization with serial twofold dilutions of the $\left[{ }^{32} \mathrm{P}\right]$-labeled run-on transcripts for $24 \mathrm{~h}$ at $42{ }^{\circ} \mathrm{C}$. The membranes were washed twice with $2 \times$ SSC containing $0.1 \%$ SDS for $1 \mathrm{~h}$ at $55^{\circ} \mathrm{C}$, treated with $10 \mathrm{mg} / \mathrm{mL}$ RNase A in $2 \times \mathrm{SSC}$ for $30 \mathrm{~min}$ at $37^{\circ} \mathrm{C}$, dried, and visualized and quantified by PhosphorImager.

\section{In vitro $3^{\prime}$ processing assay}

HeLa nuclear extract was prepared as described by Wahle and Keller (1994) and dialyzed against buffer D (20 mM HEPES/KOH at pH 7.9, 20\% glycerol, $100 \mathrm{mM} \mathrm{KCl,} 0.2 \mathrm{mM}$ EDTA, $0.5 \mathrm{mM}$ DTT) prior to use. The in vitro cleavage reaction mixture was assembled on ice with the following components: $1 \mu \mathrm{L}(100 \mathrm{fmol})$ m7GpppG capped, uniformly $\left[{ }^{32} \mathrm{P}\right]$-labeled RNA, $1 \mu \mathrm{L} 2.5 \mathrm{mg} / \mathrm{mL}$ bovine liver tRNA, $2 \mu \mathrm{L} 10 \mathrm{mM}$ cordycepin triphosphate ( $3^{\prime}$-dATP), $2.5 \mu \mathrm{L} 0.2 \mathrm{M}$ creatine phosphate, $0.75 \mu \mathrm{L} 100 \mathrm{mM}$ DTT, $0.25 \mu \mathrm{L} 50$ $\mathrm{mM} \mathrm{MgCl}_{2}, 0.1 \mu \mathrm{L} 40$ unit/ $\mu \mathrm{L}$ RNaseOut $5 \mu \mathrm{L} 12.5 \%$ (v/v) polyvinyl alcohol (PVA), and $12.5 \mu \mathrm{L}$ dialyzed HeLa nuclear extract. The reaction mixture was incubated for up to $2 \mathrm{~h}$ at $30^{\circ} \mathrm{C}$ and product recovered at intervals by extraction with phenol:chloroform:isoamyl alcohol (25:24:1) and ethanol precipitation was separated on a $6 \%$ polyacrylamide/urea gel and quantified by PhosphorImager.

\section{ACKNOWLEDGMENTS}

We thank José Garcia-Sanz for pGtetOßAc.luc3 plasmid. This work was supported by PHS grants R01 GM55407 and GM38277 to D.R.S. E.L.M. was supported by an oncology fellows training grant, PHS grant T32 CA09338, and support for core facilities was provided by PHS center grant P30 CA16058 from the 
National Cancer Institute to The Ohio State University Comprehensive Cancer Center.

Recieved January 5, 2005; accepted March 7, 2005.

\section{REFERENCES}

Choi, Y.H. and Hagedorn, C.H. 2003. Purifying mRNAs with a highaffinity eIF4E mutant identifies the short $3^{\prime}$ poly(A) end phenotype. Proc. Natl. Acad. Sci. 100: 7033-7038.

Das Gupta, J., Gu, H., Chernokalskaya, E., Gao, X., and Schoenberg, D.R. 1998. Identification of two cis-acting elements that independently regulate the length of poly(A) on Xenopus albumin premRNA. RNA 4: 766-776.

Das Gupta, J., Gu, H., and Schoenberg, D.R. 2001. Position and sequence requirements for poly(A) length regulation by the poly(A) limiting element. RNA 7: 1034-1042.

Edmonds, M. 2002. A history of poly A sequences: From formation to factors to function. Prog. Nucleic Acid Res. Mol. Biol. 71: 285-389.

Gehring, N.H., Frede, U., Neu-Yilik, G., Hundsdoerfer, P., Vetter, B., Hentze, M.W., and Kulozik, A.E. 2001. Increased efficiency of mRNA $3^{\prime}$ end formation: A new genetic mechanism contributing to hereditary thrombophilia. Nat. Genet. 28: 389-392.

$\mathrm{Gu}, \mathrm{H}$. and Schoenberg, D.R. 2003. U2AF modulates poly(A) length control by the poly(A)-limiting element. Nucleic Acids Res. 31: 6264-6271.

Gu, H., Das Gupta, J., and Schoenberg, D.R. 1999. The poly(A)-limiting element is a conserved cis-acting sequence that regulates the length of poly(A) on nuclear pre-mRNAs. Proc. Natl. Acad. Sci. 96: 8943-8948.

Juge, F., Zaessinger, S., Temme, C., Wahle, E., and Simonelig, M. 2002. Control of poly(A) polymerase level is essential to cytoplasmic polyadenylation and early development in Drosophila. EMBO J. 21: 6603-6613.

Keller, W. 1995. 3' end cleavage and polyadenylation of nuclear messenger RNA precursors. In Pre-mRNA processing (ed. A.I., Lamond), pp. 113-134. R.G. Landes Company, Austin, TX.
Levitt, N., Briggs, D., Gil, A., and Proudfoot, N.J. 1989. Definition of an efficient synthetic poly(A) site. Genes \& Dev. 3: 1019-1025.

Lewis, B.P., Burge, C.B., and Bartel, D.P. 2005. Conserved seed pairing, often flanked by adenosines, indicates that thousands of human genes are microRNA targets. Cell 120: $15-20$

Peng, J. and Schoenberg, D.R. 2005. mRNA with a $<20$-nt poly(A) tail is translated as efficiently in vivo as long poly(A) mRNA. RNA (in press).

Rao, M.N., Chernokalskaya, E., and Schoenberg, D.R. 1996. Regulated nuclear polyadenylation of Xenopus albumin pre-mRNA. Nucleic Acids Res. 24: 4078-4083.

Salles, F.J., Richards, W.G., and Strickland, S. 1999. Assaying the polyadenylation state of mRNAs. Methods 17: 38-45.

Schoenberg, D.R., Moskaitis, J.E., Smith Jr., J.H., and Pastori, R.L. 1989. Extranuclear estrogen-regulated destabilization of Xenopus laevis serum albumin mRNA. Mol. Endocrinol. 3: 805-814.

Sheth, U. and Parker, R. 2003. Decapping and decay of messenger RNA occur in cytoplasmic processing bodies. Science 300: 805-808.

Tharun, S. and Parker, R. 2001. Targeting an mRNA for decapping: Displacement of translation factors and association of the Lsm1p-7p complex on deadenylated yeast mRNAs. Mol. Cell 8: 1075-1083.

Wahle, E. and Keller, W. 1994. $3^{\prime}$ end-processing of mRNA. In RNA processing: A practical approach (eds. S.J. Higgins and B.D. Hames), pp. 1-34. Oxford University Press, Oxford, UK.

Wilusz, C.J., Wormington, M., and Peltz, S.W. 2001. The cap-totail guide to mRNA turnover. Nat. Rev. Mol. Cell Biol. 2: 237-246.

Yang, F., Peng, Y., and Schoenberg, D.R. 2004. Endonucleasemediated mRNA decay requires tyrosine phosphorylation of polysomal ribonuclease 1 (PMR1) for the targeting and degradation of polyribosome-bound substrate mRNA. J. Biol. Chem. 279: 48993-49002.

Zhao, J., Hyman, L., and Moore, C. 1999. Formation of mRNA $3^{\prime}$ ends in eukaryotes: Mechanism, regulation, and interrelationships with other steps in mRNA synthesis. Microbiol. Mol. Biol. Rev. 63: 405-445. 

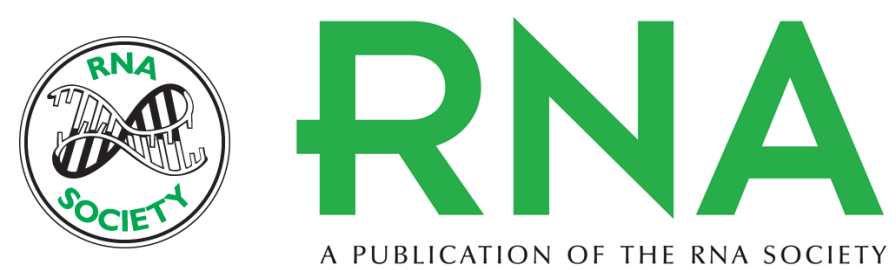

\section{The poly(A)-limiting element enhances mRNA accumulation by increasing the efficiency of pre-mRNA 3 ' processing}

JING PENG, ELIZABETH L. MURRAY and DANIEL R. SCHOENBERG

RNA 2005 11: 958-965

References This article cites 18 articles, 8 of which can be accessed free at: http://rnajournal.cshlp.org/content/11/6/958.full.html\#ref-list-1

License

Email Alerting Receive free email alerts when new articles cite this article - sign up in the box at the Service top right corner of the article or click here. 